\title{
Good Practices of Interdisciplinary International Cooperation between Universities and Local Development on Social Suffering in Urban Spaces*
}

\author{
Ida Castiglioni1\#, Alberto Giasanti'1, Osvaldo Romero², Armando Ulloa ${ }^{3}$ \\ ${ }^{1}$ Department of Sociology and Social Research, University of Milano-Bicocca (Italy), \\ Milano, Italy \\ ${ }^{2}$ International relations, University of Sancti Spiritus (UNISS), Sancti-Spiritus, Cuba \\ ${ }^{3}$ Faculty of Medicine, UNAN of Managua, Managua, Nicaragua \\ Email: ${ }^{\#}$ ida.castiglioni@unimib.it
}

Received 20 August 2013; revised 25 September 2013; accepted 8 October 2013

Copyright (c) 2014 Ida Castiglioni et al. This is an open access article distributed under the Creative Commons Attribution License, which permits unrestricted use, distribution, and reproduction in any medium, provided the original work is properly cited. In accordance of the Creative Commons Attribution License all Copyrights (C) 2014 are reserved for SCIRP and the owner of the intellectual property Ida Castiglioni et al. All Copyright (C) 2014 are guarded by law and by SCIRP as a guardian.

\section{Abstract}

This article describes areas in application of good practices which emerged from international and interdisciplinary research on social suffering in urban spaces and on change agentry with inter-cultural sensitivity, which is on the basis of a new concept of co-operation for local development. Three examples of possible good practices are illustrated: 1) Pilot action-research project by UNAN of Managua on community health and quality of life in Managua's Barrio Carlos Fonseca, an urban place of social suffering; 2) the relationship between University of Sancti Spiritus and the local Cuban community; 3 ) the action-research on the rights of citizen that the University of Milano-Bicocca, together with the Foundation Casa della Carità (local NGO), is conducting in some districts in Milan. It is important to emphasize how universities progressively raise number of tasks making them increasingly important as agents for local development. Therefore universities should be measured not only on the basis of quality of knowledge and human capital, but also on the level of embedded social capital within a certain region. Universities should increasingly become the nexus in which people can come together, ask questions, make demands and offer experiences. These social and professional practices pass through the university arena and return to

\footnotetext{
"Presented at The Second ISA Forum of Sociology, Social justice and democratization, Buenos Aires, Argentina, August 1-4, 2012. (Research Committee on Regional and Urban Development, RC21Session F, Social justice and voice: Urban suffering between transformations of the city and participation).

"Corresponding author.
}

How to cite this paper Castiglioni, I., Giasanti, A., Romero, O. and Ulloa, A. (2014) Good Practices of Interdisciplinary International Cooperation between Universities and Local Development on Social Suffering in Urban Spaces. Open Journal of Social Sciences, 2, 160-169. http://dx.doi.org/10.4236/jss.2014.21015 
their origins enriched by exchanges of new perspectives. Ideas coming from places of action and from dynamic collectivities outside, stimulate the inside through continuous co-mingling.

\section{Keywords}

Interdisciplinary Research; Social Suffering; Urban Spaces

\section{Introduction}

Universities today are called to perform a growing number of complex roles for different target groups. Therefore, aside from the task of furnishing a traditional education (undergraduate, post-graduate, specialization, doctoral courses, etc.) and of conducting research, new requirements are added. Among these we find: adult education, ad hoc courses for students from the business world, services and entrepreneurial activity, at times in partnership with the corporate world, action research, consulting, etc. To this we add the fact that universities are progressively providing more support for the needs of their local communities [1].

It is important to emphasize how universities' progressively rising number of tasks makes them increasingly important as agents for local development [2]. Therefore universities are measured not only on the basis of quality of knowledge and human capital, but also on the level of embedded social capital within a certain region. Value is added in those contexts where suitable skills resulting from constant investment in university education and professional qualification are useful. Universities must offer more and more spaces in which people (even those from abroad, and quite far away) can come together, ask questions, make demands and offer experiences. These social and professional practices pass through the university arena and return to their origins enriched by exchanges of new perspectives. These ideas that come from places of action and dynamic collectivity outside, stimulate the inside through continuous co-mingling with critical practice and knowledge that foster changes with views on action research. Thus universities become meeting grounds/a meeting ground for theories and practices that produce knowledge by placing different forms of understanding in dialog with each other and build connections while maintaining difference.

\section{Development and Cooperation}

It is obvious that development results from a complex material process involving different social agents and that marginalization is a logical consequence of the means of production in certain societies and times in history. It is thus insufficient to add adjectives to the term "development" like sustainable, local, community, participatory, integrated, lasting, alternative, etc., to contrast the competitive logic that sustains the still primary idea of development as continual economic growth. It is necessary to build or reconstruct a critical culture that is able to question the very content of development and that can strive to create a society based on quality of life rather than quantity, on cooperation rather than competition, on reduction rather than accumulation and limitless consumption [3].

If international cooperation is undergoing a time of crisis, it is because it is based on ideologies and intervention models that come from the end of World War II, which are, from a social and ethical point of view, inadequate today [4]. From an ethical point of view, more than half a century of experience has shown that cooperation is still unevenly weighed in favor of donor countries and functions toward their economic and ideological hegemony. This contributes to the widening gap between rich and poor rather than reducing it. From a social point of view, the application of a Western model of cooperation shows "exclusionary strategies of competition" [4, p. 184] in which some fight for dominance over others. This happens in an international context of dramatic change of power relationships between no longer hegemonic countries and emerging ones.

Given this, how can we open up a space of critical comparison on ideas and practices of change in which cooperation can take on the role of a research laboratory? A concrete possibility lies in taking the local community as an example [5]. The local community is made up of a strong synergy among a region, a population and a government that represents it. It is the level of organization best placed to strive for a better quality of life and to respond meaningfully to the collective needs of the population. The local community seems to be the decen- 
tered cooperation model of the future since it favors people's direct and active participation in decision-making through suitable local politics.

Furthermore, a critical approach must totally abandon the still wide-spread idea and practice that cooperation happens between donor and recipient countries and should be based on a nexus among regions, partnerships and constructive relationships between different cultural agents who acknowledge each other via the work of cooperation. A famous example of direct democracy is the Brazilian "participatory budget" experience in Porto Alegre as of early '90s. This was a grass-roots assembly of citizens' groups, neighborhood groups, grass-roots committees, etc. in which the local population decided where and how to dedicate community funds to improve quality of life. The goals of this grass-roots participation are to fairly distribute resources and to build a regional regulatory panel compatible with demands and needs of the local population.

This experience allowed the building of the New Municipium Network's Declaration Charter at the World Social Forum in Porto Alegre (January 2002) and at the European Social Forum in Florence (November 2002). The Charter was promoted and discussed under the initiative of researchers based at universities in Florence, Bologna, Milan, Rome and Venice. A large number of local Italian authorities and citizens' associations have so far subscribed to the Charter. A network of associations of local authorities and researchers has been set up with the aim of implementing the Charter's contents. "The new municipium produces new social scenarios by recognizing deeply rooted living and working practices of inhabitants originally from different countries and paces. This process produces new community relationships at a social and individual level between different people and cultures. The public space in particular is where many new and culturally different living practices are shared" [6, p. 9].

“This perspective in local development, identified with civic networks' and the growth of fair government for local societies, must not become narrowly local; on the contrary, new networks as alternatives to global ones must be built, grounded in local differences, for non-hierarchical and non-instrumental cooperation” [6, p. 4].

Building these local societies' fair networks can be defined as a bottom-up co-operation, which is also a world strategic network. This project, through the participation of Local Social Forums and Local Governments, has started building this new form of co-operation.

Taking the region as a system implies considering it as a seat of continuously transforming integration processes between nature and culture, and as a place of exchange among different communities. Such a practice requires an intercultural approach that acknowledges these differences and can put their synergy and complementarity to good use [7].

Therefore, the goal of a de-centered co-operation process is to construct a complex exchange network among local communities. These exchanges, understood as laboratories of action-research, allow comparisons of culture and different experiences as well as trials of possible alternative solutions through intercultural projects that stimulate positive change.

\section{Universities as Co-Operation Agents}

It seems urgent to revise the notion of the current culture of co-operation as an uneven balance between haves and haves not [8]. The contribution universities can bring to this discussion is an important one; even more so if they become part of this "new culture" of co-operation. Their role should remain one of training and research on the one hand, but also one of systematizing various inputs coming from social actors on the field, both locally and internationally. For instance, collecting anecdotal information from local communities in their interaction with cooperation agents and reframe them into more theoretical coherent perspectives would be an important task that would support a different direction in working with developing contexts: it would mean a more accurate and perhaps replicable intervention. More so, it would support a logic of reciprocity and exchange. In a perspective of economical de-growth, there is much more to learn about, say, recycling and self-sustainment from countries like Cuba than from the United States, but one can find this in project reports, rarely in academic literature. Activating resources for the systemization of information and inputs would create nomothetic data that could make experiences comparable and interventions transferable. Transferability of theories and practices is a topic that has in fact not received enough attention in the co-operation literature. After the demises of several aid projects from the Sixties on, there has been an awareness of the inadequacy of the transfer of technology from richer to poorer countries, but there is still little awareness that behaviors and practices can also not be transferred from one cultural context to another, unless they are reprocessed and revised with a different cultural 
framework. Not only a project should be seen through the eyes of the so called recipient, but also through a perspective which takes into account the interaction between this subject and an outsider (once donor) in a dynamic of exchange. This implies an intercultural competence, which is often a neglected subject in professional trainings for co-operation. At best, students are prepared to deal with their own emotional changes which might occur when shifting cultural context, but not enough is being done to stress the importance of recognizing differences, accepting them for what they are, work through and with them in order to construe a mutual achievable goal and prepare a setting for reciprocal learning between stakeholders.

There is space for the training and qualification in this regard of both students, faculties and staff of higher education institutions that are dealing with decentered co-operation. Most of the exchange programs between universities have the underlying philosophy that is the contact itself between people and organization to promote the recognition and appreciation of differences, stretching to the ability to work together as partners or team members. Research shows that contact with cultural differences without preparation is bound to reinforce stereotypes and divisions $[9,10]$; nevertheless very little has been done to compensate this deficiency in exchange programs, which are, at present, the core of many efforts for internationalizing universities [11].

We propose here the creation of a model of a transnational and intercultural network of universities in which this concept can be implemented. The TINU (Transnational and intercultural network of universities) should involve 1) local communities where they are based and/or communities where development projects have been set; 2) researchers both from academic settings and from agencies operating in a territory; 3) students, possibly from different contexts and/or countries; 4) faculties and staff of universities and different organizations. The idea is to have an interconnected process of learning among these subjects which all would share a platform of common language about the recognition of differences and of their potential, about the ability to process intercultural ethical issues and about the capacity of transferability. This would create a communal competence allowing the network to operate at a level of technical and humanistic performance in order to create new models of respectful interventions and creative modeling of research and applications.

This approach is a different take on internationalization that can foster, at least in this domain of studies, an ethnorelative mindset. It is through an ethnorelative perspective that the idea of partnership can assume the meaning it was evoked for, in the sharing of goals and the creation of third cultures [12-14] which encompass values, behaviors, communication styles and cognitive styles of the actors. Internationalization therefore is seen here not as a way to make our universities a more cosmopolitan place seasoned with some political correctness and a few courses taught in a different language, but as a way to prepare new citizens for an enlarged world. A world which demands more responsibility not only for a sustainable physical environment, but also for a more sustainable social environment in which intercultural competence becomes a central piece of people's education to guarantee autonomy of development and mutual learning.

\section{Good Practices of Interdisciplinary International Cooperation: Cuba, Italy and Nicaragua}

\subsection{Cuba: Sancti Spiritus}

Cuban universities are managed and conceived as territorial institutions: hence, the orientation to local development is rooted in this mutual link. This approach received additional impetus in 2006 when the Ministry of Higher Education of the Cuban Republic launched the Program Management of the Knowledge and Innovation for the Development, which along with other programs implemented by other ministries, made possible modifications in the current Cuban economic system. In this perspective universities are given an important role in LD in alignment with several economic policy guidelines from the National Governement.

It should also be remembered that according to Jocelyn Gacel-Avila [15], internationalization is an integral process that attempts to incorporate international dimensions and perspectives in the mission and the basic functions of the institution; so if one considers that the LD is an extension of the functions of the university documented by the government in the new economic model, then we can understand the role of international cooperation in the LD.

For all these reasons, the relationship of the University of Sancti Spiritus “José Martí Pérez” UNISS with local Cuban community has had a systematic development in recent years and has grown from an intercultural perspective and under university policy based on social responsibility of universities in local environments. Al- 
though the UNISS is a relatively young university, it has shown a capacity to act within a specific territory, strengthening its social, patrimonial and economic resources. The UNISS offers increasingly spaces for people to have access to knowledge, provides the answer to questions from the community leaders and provides experiences through mentoring and support to community members. It seeks to achieve a synthesis of grounded theory and practical knowledge to produce scientific research that contributes to innovation at the local level or innovative activities that contribute to the development of new knowledge and high education.

To achieve this purpose the UNISS has started several years ago an international cooperation with institutions from all regions of the world, based on a system of cooperation where cooperating agents and universities do not act as a contributor or receiver, but as active entities in a mutually beneficial relationship. Each institution contributes and receives from a constructive relationship that recognizes its counterpart as a cultural agent that enhances its performance in the local context. International cooperation is thus seen as a way to prepare the community and its players to interact in a globalized world, in a sustainable social environment where intercultural competence is central to the education of citizens to ensure the autonomy of development and mutual learning, all this must occur in a context where each participant in the partnership must show their own traditions and cultural values and interpret those manifested by the counterparty, promoting the culture and traditions and raising the ability to interact in intercultural groups.

The relationship between UNISS and the local community has the overall objective of promoting the realization of local development initiatives form cooperative in communities in the province of Sancti Spiritus, through training, advice and support to regional level and contribute to improving the life quality in these communities, local economic development indicators, and the ability to trigger participation, through management of knowledge and innovation to impulse the local development. All faculties, groups of teachers and students of the university become involved in the cooperation community-university, because the solution to local problems they face, requires multidisciplinary and multicultural intervention.

The UNISS at the end of 2011 shows significant progress in the contributions of its FUM (Municipal University filial) and faculties to local development, with participation in all municipalities and contributions specially of the Yaguajay municipality. Here, in May 2011 was organized the "Second National Workshop on University Management of Knowledge and Innovation for Development", in which the Ministry of Higher Education recognized the results of UNISS in local development endeavors. The institution has graduated five PhD in topics related to local development and another 10 applicants are under investigation in related areas. The UNISS through its FUM has participated in defining local development strategies of all the communities, acting as a facilitator of the process that has been developed by community stakeholders led by the government and with the participation of institutions and structures community. Priority development strategies are in Food Production, Environment, Housing Rehabilitation and Construction, Training, Computerization-Communication, Development of Local Industry, Energy and Sociocultural Work. In the same way all the FUM participated in at least 3 projects that taxed local development, develop scientific integration workshops for development that promoted the incorporation of new agents and actors in this activity in an intercultural relationship. The FUM participated actively in local development actions in collaboration with the local working groups for local development; some local filial are involved in more than three projects as is the case of Taguasco, Fomento and Cabaiguán, among them highlights the projects PIAL and PALMA. The local filial developed postgraduate and capacitation programs and training focused entirely to meet the needs for improvement in communities-in particular those associated in cooperatives farmers interested in seed varieties - and procedures for obtaining results through higher production. Under the guidance of the coordinators at the University of PIAL and PALMA some of these projects, tackled social problems such as alcoholism, prostitution, violence and unemployment.

The UNISS cooperates also with the Universities of Havana, Matanzas and the experimental station Indio Hatuey, where Masters programs in Business, Environment, and in Pastures and Forages have been developed. Currently the institution is developing other programs that are priorities for local development initiatives as a master and a diploma in Community Development Diploma in Project Management for local development, MSc Sustainable Tropical Agriculture, a diploma in "Sustainable Agriculture" and it is planning a PhD with the University of Alicante in Spain in "Local Heritage Management", emerging from a successful postgraduate joint program in place for many years. There is a need to assess the actual impacts of local development projects. In this regard four doctoral dissertations are trying to measure it. For the same purpose ten workshops have been developed to integrate the actors from the provincial level to the community level.

Also UNISS directly contributes to local development, in conjunction with the FUM specific projects of in- 
novation and training programs at the local level on problems identified by the communities such as: identification of energy alternatives for rural non-electrified, energy self-sufficiency through the use of waste for biogas production, mathematical modeling of vectors and its epidemiological influence, project for the development of small and medium enterprises at the local level, government advice on development programs, local agricultural innovation, introduction of motor cultivators, mitigating the effects of drought, use of probiotics in meat production locally, the use of geo information technology as a tool for promoting and monitoring local development.

In this context, the UNISS, in cooperation with the University of Milano Bicocca, has in its project portfolio two proposals which seek to give new impetus to support efforts of local human development in rural communities in the province of Sancti Spiritus. Both projects will help promote local development with attention to vulnerable groups and gender equity.

Related to the international cooperation to promote local development, the UNISS has enhanced the cooperation with Europe through the relationship with the University of Milano Bicocca, in Italy, by creating a double recognition of a graduate program in management of public policies and community development that contribute to local development from an academic perspective. This implies mobility of students and faculties. A similar program has been in place with the University of Ghent in Belgium, through which our institution has supported the development of biogas as an energy source locally. The relationship with other universities in Spain, Italy, Mexico and Germany strengthened bilateral relations between countries, while the staff is nurtured with the best preparation of its members and facilitates the rapid development of infrastructure and resources to help local development in Cuba.

Cooperation actions of the UNISS made possible to participate in six international projects funded by international agencies and where the UNISS acquired resources to enhance the infrastructure of laboratories, computer equipment and material resources. A new cooperation has begun with Kwantlen University in Canada, aimed at implementing sustainable methods of agricultural production at the local level, where students from both universities work together.

To ensure the contribution of cooperation to local development, the UNISS implemented a procedure for managing the internationalization. It started from the identification of local needs of development, which eventually reconciled by identifying international counterparts to ensure coverage of communitarian and institutional demands. This procedure has enabled the institution to increase the number of teachers and students participating in international efforts to contribute to local development. In turn, the international and intercultural contact has fostered communication ability while increasing their capacity to act in communities [16].

The ultimate goal is to create local skills lab communities allowing communities to identify endogenous resources and use them according to their own development with the smooth participation of all actors.

\subsection{Italy: Milan}

A drawing, given to Alberto Giasanti years ago by the kids of a juvenile detention center, is the starting point for speaking of cities, imagining them as two worlds and two populations that face off and fight over the urban spaces or, also as an enormous hungry organism, with many heads, that swallows ever larger parts of territory with a kind of iconoclastic fury that leads to the paving of everything possible and beyond in a unstoppable frenzy. It's a drawing of two cities: one above, one below; the first is mirrored in the second. The two cities are drawn as if looking in a large mirror that enlarges, deforms, shrinks the images and combines them in a grotesque way so that the conflicts seem to look like riots between tragic and at the same time comical characters or instead. The colors are violent, bright, disquieting and mostly red in the city above and dark blue, purple and black in the city below that is inhabited by the people of the abyss. The city above is inhabited by automatons, the geometric figures of the two dimensional world. Had the artist been Chagall, one could have imagined a sunny golden house for the world above and a black sparkling lunar house for the world below. To one side is a rope ladder with the colors of the rainbow, should the two worlds decide to have a contact. The citizens of the city above seem divided into different layers hierarchically tending to occupy pre-established and possibly homogeneous places. The citizens of the city below are considered the people of the abyss, the negative and unspoken side of the civilization above; a sort of cast off, social rejection, obscure instinctual force, a Hades of the collective psyche. Looking into the subterranean city it is like when one takes the subway and smells the smells of a tired, unhappy humanity, compressed by the weight of daily life and surrounded by dark tunnels, almost timeless. It is a look that focuses on the faces of men and women, pausing for the necessary time to read on 
every face the story of the day, but also the postures of the bodies, their sizes and then their clothes to figure out the job of those who wear them. But the humanity that most of all catches the eye is that of the poor, the beggars, the stricken with disturbing faces because they are indicators of untold suffering and sadness that in the city above doesn't touch you because it is possible to pass on, not see, be insensitive. Below in the subway you can't pretend to not see, to not hear, not feel, even if they are often cries without voices and sounds without music. The humanity of the underground seems to live in a collective dream or on the stage of an absurd theatre, as if in reality we lived somewhere else. The atmosphere is always of absence as if we were pressed by the problems that arise from the many bodies of men and women that are waiting for something [17].

This is a starting point to talk about Milan and the strategies to put together the two cities, of above and below, like in "Città Invisibili" of Italo Calvino [18]: "I will put together, piece by piece, the perfect city, made up of fragments mixed with the rest, instants separated by intervals, signals that one sends without knowing who will pick them up”.

The University of Milano-Bicocca, together with the Foundation Casa della Carità, is conducting an action-research on the rights of citizen in some districts in Milan. Six themes of research: under age foreigners not accompanied, migrant people, health and services, social marginality, prisons, housing. In the relationship university-local community it is very important the role of the University as a development agent in society, interacting with citizens and institutions, which is strengthened by research activity, interaction, sensitization, education, training and capacity building, professional apprenticeship and participatory field projects. It is important to emphasize how universities' increasing number of tasks makes them increasingly important as agents for local development. Therefore the university should be measured not only on the basis of quality of knowledge and human capital, but also on the level of embedded social capital within a certain region.

The research-action project aims to provide a significant contribution to help improve the quality of life in Milan, through good practices regarding the conditions of ill-being of the metropolitan area. The objectives are: a) establishing more effective public policies in Milan; b) making appropriate public expenditure; c) increasing the ability to make public interventions in order to concretely change people's daily life; d) giving effect to the rights of citizenship.

The considered area for research is a defined urban area (the neighborhood Niguarda) and the stakeholders are: 1) Casa della Carità whose knowledge of pragmatic problems in the city of Milan is very respected; local citizens' associations; the University of Milan Bicocca and Polytechnic of Milan that will engage their experiences on research, directed to take into account the voice of stakeholders and knowledge they bring, and concerning the design of public policies.

The project aims to address two critical issues regarding the effectiveness of policies in Milan: on the one hand, problems and needs of individuals today are recognized and treated with established and possibly "old" administrative categories, unlikely to be effective; on the other hand, the limited financial resources.

The overall action aims to develop a methodology for public action which may be applied to other contexts in order to accompany Milan in a reorganization of social policies.

The project starts with a first action for implementing the action research in a microarea of Niguarda neighborhood in reference to Assessorato alla Casa: the research team has identified a substantial number of housing owned by the municipality of Milan, which are partly vacant. This is not a degraded environment in terms of construction and this is an important factor that allows one to focus on issues of residency not concerning the structures and physical conditions, which usually absorb attention and resources, but practical issues dealing with living conditions of the inhabitants.

The operational phase includes: 1) the organization of a garrison of listening to the ensemble of buildings that will be chosen at boot time, in order to collect experiences, information and knowledge on the context; 2) that the garrison itself with the rules necessary to encourage the people to speak out, listen, and proceed on the basis of the combination of information from others who work in various capacities in the area. This will be coordinated by the University of Milan-Bicocca; 3) collected data on both cases will be used to identify individuals and families who have a plurality of problems and therefore require a plurality of operations and resources; 4) data will be processed to investigate: a) what issues arise from the combination of different sources and forms of knowledge; b) what policies and services are at stake, with what resources, what items of expenditure borne by the budgets of the departments. Mapping the flows of spending and the ways in which it is used will be one of the methodologies; c) what other potential resources of the informal context, i.e. people and their relationships, are likely to be triggered, supported and combined with public resources. The research results will be used to 
formulate proposals to replicate the survey in other micro-areas. The pilot project promoted by University of Milan Bicocca with the Politecnico of Milan and Casa della Carità, in close collaboration with the Municipality of Milan, through the activities of the interdisciplinary action research, will be the instrument for the promotion of good practices of active citizenship, based on actual rights enactments. In this way, universities, community and local authority intend to implement sound strategies for intervention through which recognizing diversity so that they can become value added and not an obstacle to the dynamics of communities and organizations. Accepting diversity is a journey that often contrasts with the common sense of people who are brought to recognize their own kind and not strangers, but managing diversity is also becoming a crucial challenge through which organizations, institutions and services will grow and develop creatively. Purpose of these actions is putting an end to the vicious cycle of the so called "safety urban research" where the solution to fear is the humiliation of others, considered foreign and not citizens.

\subsection{Nicaragua: Managua}

Let's sense beforehand this part as one of the principal products of the interdisciplinary research in the neighborhood Carlos Fonseca Amador of the District V of Managua [19]. The work was realized by a team under the direction of the Faculty of Humanities and Juridical Sciences and the Faculty of Medical Sciences; they present the results that are oriented to develop capacities directed to optimizing the cultural resources of the settlers to raise the quality of life of the community from a health perspective.

Research over the last fwe years has shown the community need to have a document that compiles history, culture and identity of the neighborhoods of Managua. The intention is that of strengthening culture and identity of the residents in order to be able to work with viable practices of helth prevention.

Research conducted by Carlos Fonseca highlights the different cultural variables impacting health practices. The neighborhood, founded in 1989, is located in the sector known as the oriental neighborhoods of Managua; it is delimited by two redressed riverbeds that run from south to north and other one of South to North-East, as well as by the market Roberto Huembes by the South.

Health issues are relatively stable in the neighborhood. Its proximity to the Center of Health Pedro Altamirano; the Hospital Roberto Calderón-Manolo Morales-and the hospital of the child Manuel de Jesus Rivera "La Mascote" might be a reason. Nevertheless it is relatively stable because the preferred way to solve health related issues is the natural, traditional medicine or faith based practice.

Social hazards that the residents face are noise pollution; delinquency; habitual vagrancy, drug addiction, social and domestic violence. These and other components have led researchers to think that the neighborhood is in a state of deficiency vis a vis health security.

The study monitors the problematics of the community, which will have to be treated with the leaders and settlers to offset their negative effects.

The Cultural and anthropological aspect of the research is going to be particularly useful for the neighborhood, especially for the political, civil and religious leaders who are trying to find a solution for petty delinquency, habitual vagrancy, "pandillerismo", drug addiction, and the overrall health of the community.

A sample of 169 family holds was used for the survey of the neighborhood needs. The criterion was of picking a family every 5 houses; attention was paid to represent different economic conditions. Focus groups were also run with leaders and women who were part of the initial neighborhood.

There is no up to date census. There are 560 houses exist and in some residencies up to four families can co-exist. In the surveyed 169 residencies, researchers counted 291 families (1351 individuals).

The distribution of the population according to sex and age is similar to the characteristics of the population of the country. $54.7 \%$ is female and an important proportion of the population is made by young females; women over 60 represent only $5.1 \%$ of the polpulation, while people under 19 represent $37 \%$ of the population. In relation at the level $44.2 \%$ has reached secondary education, $20.3 \%$ primary education and $17.2 \%$ has a university degree. Only $2.5 \%$ is illiterate.

In general, it is calculated that in the neighborhood there are 5000 inhabitants approximately. For the most part the population is made by younger females (61\%). The average of ages among the interviewed population is the following one:

Typical activities of this population are: washing, ironing, making tortillas, refreshments; housewives sell nacatamales, small businesses in the oriental market; some of them are employed as civil sevants; finally there is 
a percentage of them who is unemployed, mostly single mothers. Due to the situation of crisis some settlers have left to Costa Rica, El Salvador, The United States and Spain in search of better standards of living. The majority has left towards The United States and Costa Rica. In relation to the labor situation of the polled ones, $80 \%$ of the sample works and $20 \%$ does not have any type of remunerated work. Of them, $40 \%$ is occupied in housekeeping activities.

The main health problems that the population of the neighborhood faces, are respiratory infections, diharroical diseases, the fastidiousness and the illegal dust-bins. Among other problems they indicate little water supply, little security, the speeding in the track and the presence of poddles in the streets. As for the levels of education in the community, most of the population can read and write, a level being reached in ascending/rising order among children in primary education.

There are many traditional habits that have a great meaning in the daily life of the population. Woman's place is thought to be in the house, while men's in the public spaces. Women's double presence is completely expected.

The process of socialization starts from infancy: girls are learn what is allowed and what is not. Researchers think that in the neighborhood, the process of socialization has changed since governmental and non-governmental organizations have promoted spaces for the diffusion of childern's rights. This has inevitably created a gap among generations in the conception of women and children's upbringing.

\section{Preliminary Conclusions of the Study in Nicaragua}

The principal element of social integration for the inhabitants of the neighborhood is the historical process of conformation of the same one, the fact of sharing a territory that has been the result of a process of negotiations and the political will helping to strengthen the identity among its settlers. Other components of integration are the consanguineous bows among the families: being a descendant of a founder of the neighbourhood make people a part of that territory, no matter where they eventually live. This is a strong trait of the process of identity construction for this population.

\section{Conclusion}

It is still premature to draw any conclusion from the above mentioned actions and projects. However, given the general crisis of welfare systems, both in Europe and in most industrialized countries, rethinking the role of universities in society, particularly public founded institutions, is a must. Only by strengthening ties with local needs and territories and by offering substantial expertise can one bypass endemic political corruption. The wish is also that getting involved per se, from all stakeholders perspective, is a statement of citizenship, a model to be looked at and replicated in society in order to create more critical mass around change. Change has been a leit motiv of the last decade. However, most people expect change but do not embark on it. These practices are examples of involvement in societal change at root level that can be done in less industrialized countries as well as in post-industrial societies of contemporary Europe.

\section{References}

[1] Boulton, G. and Lucas C. (2008) What are universities for? LERU, Leuven.

[2] European Commission (2003) The role of the universities in the Europe of knowledge. European Commission: Brussels. www.europa.eu

[3] Latouche, S. (2010) Farewell to growth. Polity Press, Cambridge.

[4] Carrino, L. (2005) Pearls and pirates. A critique of aid development cooperation and new multilateralism. Erickson, Trento.

[5] Castiglioni, I. and Giasanti A. (2012) Good practices of interdisciplinary international cooperation between universities and/universities and local development. Proceedings of the Conference University 2012, 8th International Congress of Higher Education, La Habana, 13-17 February 2012, 24-32.

[6] Magnaghi A. (2003) La carta del nuovomunicipio (The charter of the new municipium). European Social Forum, Saint Denis, 1-10.

[7] Giasanti, A. and Missoni, E. (2011) Global health and development as an interdisciplinary and intercultural opportunity 
for interuniversity cooperation. The 2th National Congress CUCS on University Cooperation, Padova.

[8] Castiglioni, I. and Giasanti, A. (2010) Co-operation for development as a way to internationalize universities. Proceedings of the Conference University 2010, 7th International Congress of Higher Education, La Habana, 8-12 February 2010, 43-51.

[9] Pettigrew, T.F. (1997) Generalized intergroup contact effects on prejudice. Personality and Social Psychology Bulletin, 23, 173-185 http://dx.doi.org/10.1177/0146167297232006

[10] Stephan, W.G. and Brigham, J.C. (1985) Intergroup contact: Introduction. Journal of Social Issues, 41, 1-8.

[11] Boffi, M., Castiglioni, I. and Giasanti A. (2011) Contemporary universities as agent for local development. The 1st UNISS International Scientific Conference, Yaya Bociencia, 1-8.

[12] Bennett, M.J. (2004) Becoming interculturally competent. In: Wurzel, J.S., Ed., Toward Multiculturalism: A Reader in Multicultural Education, Intercultural Resource Corporation, Newton.

[13] Bennett, M.J. (2013) Basic concepts of intercultural communication. 2nd Edition, Intercultural Press, Boston.

[14] Castiglioni, I. (2009) Difference exists. Managing diversity in the organization of services. Franco Angeli, Milano.

[15] Gacel-Avila, J. (1999) Internationalization of superior education in Latin America. Reflections and guidelines. OUI/ AMPEI/Ford Foundation, México.

[16] Romero Romero, O., Guerrero Cabrera, A. and Méndez Hernández, O. (2012) Process for the management of the internationalization of the University of Sancti Spiritus. Proceedings of the Conference University 2012, 8th International Congress of Higher Education, La Habana, 13-17 February 2012, 66-74.

[17] Giasanti, A. (2011) Impressions between dreams and reality. Souq Quaderni, N.4. www.Souqonline.it

[18] Calvino, I. (1996) Le città invisibili. Mondadori, Milano.

[19] Universidad Nacional Autonoma de Nicaragua UNAN-Managua, Facultad de Humanidades y Ciencias Juridicas, (2010) Multidisciplinary project. Unan Managua-Unimib Diagnostico Barrio “Carlos Fonseca Amador”, Distrito V Managua, Nicaragua. 